\title{
Electronic Information Superhighway: The Sri Lanka Journal of Child Health joins the "on line" cohort
}

\author{
Sri Lanka Journal of Child Health, 2001; 30: 53-4
}

(Key words: internet, worldwide web)

The year was 1836. Cooke and Wheatstone patented the telegraph which revolutionised human interactions and inter-personal relationships. The telegraph used Morse Code, a series of dots and dashes, for communication between humans. In 1858, in a landmark event, a transatlantic cable enabled instantaneous communication across oceans for the first time. Although this cable remained viable for only a few days, subsequent ones laid in 1866 were completely successful $^{1}$. Today there are over 186,000 miles of undersea cables enabling widespread contact between individuals and organisations. In 1876, Alexander Graham Bell invented the telephone which is today the pivotal instrument on which many different modalities of communications are based.

In 1957, responding to the Soviet threats in general and "tin can in the sky" Soviet Sputnik Satellite Programme, American President Dwight D. Eisenhower set up two agencies for the future ${ }^{2}$. One was the Interstate Highway System and the other was the Advanced Research Projects Agency (ARPA). The ARPA attracted some of the most brilliant minds in the USA and in 1962 they broadened their horizons into computer technology. From 1962 to 1968 they developed the Packet-switching Networks which became the indispensable tools for computer data transfer. In 1969 the first connection between two computer systems was made. This was the actual birth of an International Network, the ARPANET, the precursor of the modern INTERNET or the WORLD WIDE WEB. The system crashed after a few seconds but the revolution had just begun. In 1972 the first public demonstration of ARPANET between 40 computers took place. 1973 saw the first international connections to the ARPANET and global networking became a reality. In 1977 electronic mail and the INTERNET took off like a house on fire. The WORLD WIDE WEB, which links millions and perhaps billions of computers across the globe, came into existence in 1991 and the world has never been the same after that. In 1997 the Internet had 19.5 million hosts, 1 million World Wide Web (www) sites and around 72,000 News Groups. Together with these developments in the USA, the Interstate Highway System of Roads too developed beyond anyone's imagination and connected many towns and regions in even the most remote areas of the land. The ARPA programmes ultimately led to the development and growth of the World Wide Web linking a tremendous number of individuals and organisations. It is thus no surprise at all that this modality is today called the Electronic Information Superhighway.

The rate at which the Internet has expanded and the extent to which its uses have broadened have confounded even the experts. Today it is used for communication, dissemination of information, commercial needs like advertising and purchasing, banking, continuing medical education and a whole host of other purposes. It has developed to such an extent that if one is not conversant with "browsing of the net", as it is generally known, one would certainly be at a disadvantage and is at risk of being left behind. This is particularly true in medicine and paediatrics as the rate at which advances are made is phenomenal. It would be humanly impossible to keep up to date without the help of an efficient and willing slave like the modern Electronic Information Superhighway.

The Annual Scientific Congress of the Sri Lanka College of Paediatricians, in August this year, had two presentations on the usefulness of the Internet. One dealt with the diagnosis and management of a very rare disease entity ${ }^{3}$ and the other chronicled a fountain of information on infectious diseases and vaccines ${ }^{4}$. In the former, a famous world authority on the disease was contacted over the Internet and the management of the child undertaken by remote control. In the second presentation, it was demonstrated that current information related to selected topics on infectious diseases and vaccines could be easily accessed through a specific web site.

It is however appropriate at this juncture to also add a cautionary note. Most of the information en the internet, especially at the reputed medical sites, are reliable and well authenticated. However, due to the fact that the electronic scenario has so rapidly expanded, it has not been possible for any authorita- 
tive institution to keep tabs on what is in it and generally act in "policing" the internet. The result is that, at least in some instances, untrustworthy and nonauthenticated pieces of information have managed to creep into the net. One does indeed need a vigilant eye and a discerning brain to deal with the information in the internet.

The Ceylon Journal of Child Health was born in the fifties and was published annually. Changing with the times in the new millenium, in the year 2000, it became the Sri Lanka Journal of Child Health and was simultaneously converted to a quarterly publication. From this issue in September 2001, just under two years from its transformation, our journal has taken one further giant step and joined the "on line" cohort in the Internet.

The specific web addresses are :-

\section{www.medinet.lk/journals/childhealth.asp and} www.srilankahealth.com/journals/childhealth.asp

These are free domain sites and there are no payments involved for accessing our journal electronically. We expect that the e-version would enable many more readers to be in touch with our journal. In today's jargon, we have taken a quantum leap in going "on line" just a short time after becoming a quarterly publication.
A different page of this issue of the journal contains useful information for the discerning reader on the different internet sites for accessing information and enabling literature searches. It is hoped that the conversion to the simultaneous e-version would be most useful to all medical and allied personnel in Sri Lanka and abroad, to access the Sri Lanka Journal of Child Health, literally at the press of a button.

\section{References}

1. History of the Internet, 2001; available from: $\leq$ http:/www.netvalley.com>

2. USSR launches Sputnik. 2001; available from: $<$ http:/www.netvalley.com/archives/mirrors/dave marshtimeline-1.htm>

3. Rayes M L M, Lamabadusuriya $\mathrm{S}$ P, Wickremasinghe $\mathrm{P}$. Information technology in rescue of paediatricians in Colombo. Proc. Sri Lanka Coll. Paediatricians Ann. Sci. Congress 2001; 2(2): 60.

4. Perera B J C. Electronic information system for infectious diseases and immunisation. Proc. Sri Lanka Coll. Paediatricians Ann. Sci. Congress 2001; 2(2): 22.

\section{B J C Perera} Joint Editor 
